\title{
When Clapping Data Speaks to Wii: Physical Creativity and Performative Interaction in Playground Games and Songs
}

\author{
Jennifer G. Sheridan \\ London Knowledge Lab, 23-29 Emerald Street \\ London WC1N 3QS \\ j.sheridan@ioe.ac.uk
}

\begin{abstract}
In this paper, we explore how exertion interfaces can promote physical creativity and the role that this might play in performative interaction. In particular, we are interested in exploring how to design and develop devices and applications which use physical interaction, or exertion, to promote performative interaction or the witting transitions between observing, participating and performing. Using the Nintendo Wii as an exertion interface, we are updating, analysing and representing a small selection of clapping games found in the Opie Collection of Children's Games and Songs in the British Library and emerging from ethnographic studies of playgrounds in London and Sheffield, UK. We describe the Physics of clapping and associated technical issues, the design of a low-fi, open source exertion interface and the analysis of a participant study. We suggest guidelines for designing for physical creativity, namely kinesthetic literacy, performative interaction and believability, and conclude with a discussion of future considerations.
\end{abstract}

Performative interaction, physical creativity, exertion games, exertion interfaces, kinesthetic literacy, Physics of clapping, playground games and songs, folklore, Opie archives.

\section{INTRODUCTION}

Interaction with digital technology is becoming increasingly physical. This growing trend is evident in the recent commercial success of interactive games and devices such as Konami Dance Dance Revolution [17], Nintendo Wii Remote [21], and Activision Guitar Hero [1]. These interfaces require participants to move their bodies around in physical space to interact with the system and each other. An advantage of these devices is that they have a 'low entry fee' [32], meaning that anyone can immediately engage with the system through simple physical movements and can disengage with minimal effort. However, despite these systems encouraging participants to move, the range of possible movements is generally quite limited. For example, with Guitar Hero, users can only strum or press buttons on the guitar to trigger digital effects. As such, the possibility of these interfaces for promoting physical creativity has largely been underexplored.

Physical creativity focuses on the "creative process" $[9,10]$ and specifically on the ability to innovate through exertion. It goes beyond memorizing a procedure and differs significantly from mimicking movement in that physical creativity focuses on exertive movements of the body as self-expression, improvisation and imaginative play. People who engage in physical creativity exhibit their physical skill and agility through breaking from simple routine by elaborating on, extending, or reconfiguring patterns of movement. For example, a karate master will develop a new way of blocking a blow, or figure skater will design a new spin. In other words, physical creativity focuses on remaking over reproduction.

In analyzing young people's media production, Burn and Durran [7] use Vygotsky's notion of creativity, which suggests that creativity is a combination of reproduction and innovation and is closely related to play [31]. Burn and Durran describe how children learn the meaning of symbolic substitution through the manipulation of physical objects in playful activity and how such activity has implications for intellectual development. Our interest is in exploring how playground games, which are highly exertive, structured repertories of play that are learned and apparently rehearsed and reproduced, relate to innovation, transformation, invention and improvisation [7]. To do so, we are developing an exertion interface system for updating, analysing and representing a small selection of playground games found in the Opie Collection of Children's Games and Songs [22-24], as well as those emerging from ethnographic studies of activities currently found on playgrounds in Sheffield and London [12] and being archived at the British Library [6, (Jopson) 12].

In this paper, we describe the development and 
testing of an exertion interface for capturing playground "clapping" games and songs using the Nintendo Wii and an open source environment for developing applications. While a multitude of motion tracking and gesture systems exist, many of these systems are costly and require extensive set up and/ or training. Our intention is to develop a low-cost and low-fi system that could be used for both teaching and research - for allowing children to record and playback playground games as well as for capturing, analyzing and visualizing 3D movement data.

We begin with a description of our project and how novel devices and technologies can promote performative interaction [2, 13, 26-29] and the role that this might play in promoting physical creativity. We then describe the Physics of clapping and associated technical issues and the design of an open source tangible exertion interface. We present our participant study and analysis, and provide a set of guidelines for designing for physical creativity. We conclude with a discussion of future considerations.

\section{BACKGROUND}

In 1944, Iona and Peter Mason Opie began collecting, archiving and classifying hundreds of nursery rhymes and songs from written sources - including the known facts about origin and variants. Their seminal publications, such as The Oxford Dictionary of Nursery Rhymes [22], have influenced throngs of folklorists. In the 1950s they corresponded with teachers to explore school-aged children's lore and produced The Lore and Language of Schoolchildren [23]. In later field work and publications, such as [24], the Opies refuted the idea that mass media negatively affected or extinguished traditional games and their vibrant testimony and audio archives stands as lasting proof that children's traditional games thrive in streets and playgrounds (Figure 1).
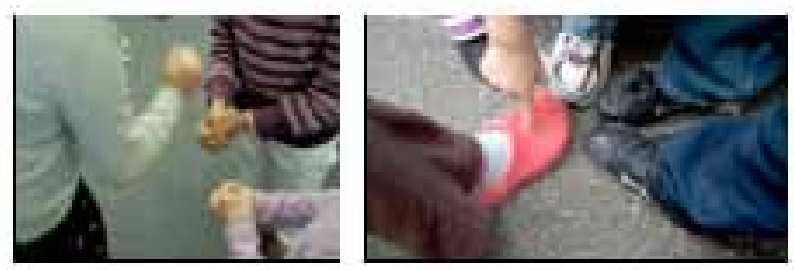

Figure 1. Playing Coca-Cola (left) and Black Shoe (right).

Our intention is to carry forward this seminal work using a three-pronged approach: digitizing material from the collections as a new digital archive at the British Library; carrying out a two-year study of playground culture in two primary schools, one in London, one in Sheffield; and thirdly developing a suite of games for the Nintendo Wii [21]. This paper focuses on the latter - on how to develop a system for allowing children to capture playground games; and, to develop a tool to allow researchers to investigate playground games. Rather than developing a system for archiving all playground games, our prototype application focuses on clapping games.

Clapping is an exertion activity that requires physical movement, or exertion, from the participant and as such, our work aligns with emerging research in exertion interfaces [19]. Exertion interfaces are defined as interaction with technologies which focus on intense physical effort from the participant, such as jogging [20], swinging an object around the body $[26,27]$ or jumping up and down [3]. Preliminary studies with exertion interfaces suggest action itself is central to meaning mapping [27, 29] and that exertion interfaces can have positive effects on personal health, moral character and the human spirit even when participants are not in the same space or are participating at different times [28]. However, physical creativity in exertion interfaces has largely been underexplored.

Exertion interfaces are often rule-bound, focus on competitive play, and introduce the concepts of winning, combat or conflict [20]. Salen and Zimmerman [25] describe the variability of formal rules in games. Our research focuses on developing exertion interfaces which are a combination of highly rule-governed Ludic play (such as clapping games) and promoting 'Paidia' [8] or open play - the often shared, anarchic and spontaneous play found in improvisation and live performance. Giddings describes these conceptual oppositions as rulebound play and emergent play [15]. The playground is a particularly good "setting" for exploring these conceptual oppositions in play, as described in Richards' [12] ethnographic observations of children performing improvised martial arts movements, and in Bishop's [12] description of the clapping game Eeny-Meeny Dessameeny.

Developing an exertion interface for the performative activities found on a playground is no easy task they are a complex combination of music, physical movement, gestural repertoires, the imaginative use of found physical objects and environments as well as language (see $[4,7,12,16,18,33])$. Current research is undertaking studies to investigate the relationship of transmitted [(Bishop and Willett) 12, 33] and performed repertoires - the inherited patterns of play in action, language and music, and the impulse to transform, innovate and improvise in performance. Our interest is performative interaction $[2,13$, 2629] -in how participants transition from observing to participating to performing through: wittingness (awareness of the performance frame); technical ability (acquiring and execute simple routines); and, interpretive ability (the ability to develop a method of making the performative activity uniquely their 
own - an embodiment of their own skill) [26, 27]. In particular, we are interested exploring how to design and develop an exertion interface for promoting "witting transitions in performative behavior" [26] as a way of promoting physical creativity.

In designing an exertion interface for promoting physical creativity, a number of questions emerge: How do we design, develop an exertion interface for promoting physical creativity in rule-bound and emergent play? How does performative interaction relate to the multimodal "process of transmission" [12, (Bishop and Willett)]? How do we design our system to allow for rehearsing, recording, reproducing and remaking? How do we preserve the aesthetic of playground games and songs when digitizing playground activities? What are the affordances of playground games and songs? Why do girls (rather than boys) play clapping? What do they learn (physically, socially) by getting to be good at clapping? Does adopting the transgressive, subversive aspects of play into a more public, shared space like a computer game (or indeed the BL website) in effect 'edit out' these more transgressive elements [(Mitchell) 12]? In order to address some of these questions, we begin with an examination of the Physics of clapping.

\section{PHYSICS OF CLAPPING}

Key Question: How do we (accurately) reflect clapping in the physical world with clapping in the digital world?

The action of clapping may intuitively seem like a relatively simple pattern of movement however, clapping movements are complex: the position and orientation of the hands changes quite dramatically from one move to the next. For example, each hand has a different start and stop position; a different magnitude of movement (e.g. a little/a lot of movement); and, the speed and acceleration of each movement is lightning fast. As such, the 'Physics of clapping' presents many technical challenges and opportunities for the designer when developing clapping game.
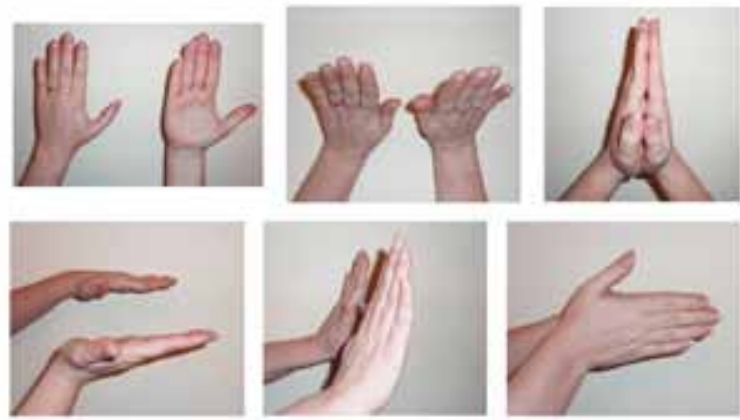

Figure 2. Top and side view of a 'three way clap'.
Let us consider the clapping game I Went to a Chinese Restaurant which is always played with a partner. In one version of this "three-way" [24] clapping game (Figure 2), children begin with a "down up clap" (D/U), then clap their partner (C/P) before finally clapping their own hands together (C/O) (see Marsh's Movement Key [18, p. 342]).

Many Wiimote games on the market only use one device per participant however in clapping games both hands are equally important and always mirror the partners' hands (Figure 2). The position, orientation and direction changes rapidly (Table 1). Each continuous move creates a rhythm, like a drumbeat or a pulse, throughout the song. In designing our game, we need to consider how to capture the rhythm and flow of this movement data from two hands moving in many positions and orientations in physical space when participants are usually mirroring each other at a very rapid pace.

Table 1. Movement, position, lyrics and speed of clapping.

\begin{tabular}{|c|c|c|c|}
\hline Movement & $\boldsymbol{N}$ & ric & $\rightarrow 6$ \\
\hline Movement Key [18] & $\mathrm{D} / \mathrm{U}$ & $\mathrm{C} / \mathrm{P}$ & $\mathrm{C} / \mathrm{O}$ \\
\hline Position / Orientation & & 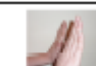 & \\
\hline \multirow[t]{3}{*}{$1^{\text {st }}$ Line of Song } & I & went & to $\mathrm{a}$ \\
\hline & Chi- & nese & Res- \\
\hline & ta- & ur & ant \\
\hline Speed & $>0.5 \mathrm{~s}$ & $>0.5 \mathrm{~s}$ & $>0.5 \mathrm{~s}$ \\
\hline
\end{tabular}

Wiimote games often rely on: the action of swinging; the importance of follow-through; and, on hitting a stationary target. For example, in Wii Bowling or Wii Golf the point of impact is a digital target in which participants attempt to hit by performing one swinging motion. Conversely, in Wii Tennis, participants respond to a moving target which has a (semi) predictable trajectory.

Table 2. Comparison of design variables for Wiimote games.

\begin{tabular}{|l|l|l|l|l|}
\hline Game & Bowling & Golf & Tennis & Clapping \\
\hline Target & Multiple Static & Singular Static & $\begin{array}{l}\text { Singular } \\
\text { Moving }\end{array}$ & $\begin{array}{l}\text { Multiple Static } \\
\text { + Moving }\end{array}$ \\
\hline $\begin{array}{l}\text { Point of } \\
\text { Impact }\end{array}$ & Other & Other & Other & Self Other \\
\hline Partner & No & No & Yes & Yes \\
\hline Continuity & One move & One move & Multi Move & Multi Move \\
\hline Mirror & No & No & No & Yes \\
\hline Trajectory & User-led & User-led & $\begin{array}{l}\text { (Semi) } \\
\text { Predictable }\end{array}$ & Predictable \\
\hline
\end{tabular}

A clapping game is a combination of these factors: 
participants respond to a moving target that has a predictable trajectory (Table 2 ). In addition, a clapping game has multiple points of impact and the transitions between these points are extremely quick - much faster than for example, in Wii Tennis. Our game will need to anticipate and respond to these quick transitions.

Another important distinction can be made between current Wiimote games and a Wii Clapping game if we examine the point of impact in more detail. In Wiimote games, even in Wii Boxing, participants are always hitting 'other' - never self. In a clapping game, participants either clap their own hands together or their partner's - the point of impact is both self and other. In designing a clapping game, we must consider that in some instances, participants only external reference point will be their own body. How will digital representations (e.g. graphics, haptics or audio) provide participants with an external frame of reference and how will this help to guide participants to correctly position and orientate themselves in physical space?

A final (but not exhaustive) point to consider is how will our design articulate the relationship between learning repertories and physical creativity. The example above of I Went to a Chinese Restaurant is only one interpretation and tens of interpretations (type of clapping, singing, words) exist. Will our game emphasize cultural value (e.g. choosing 'cool' moves), skill development (getting faster, more complex over time), or both? How do we design our system to allow for multiple interpretations of the same clapping game? How can we use technology to provide different interpretations of clapping data? How do we scale clapping?

\section{DESIGNING FOR PHYSICAL CREATIVITY}

We have outlined a number of important points to consider when designing a prototype exertion interface for both rule-bound play and emergent play. As Giddings [15] discusses, our system must consider play between simulated action/space and physical space; play with digital toys and physical toys; and, play between software and physical bodies.

\subsection{Kinesthetic literacy}

Applying kinesthetic literacy as a guideline for design for physical creativity allows children to know the limitations of both self and other, giving them an opportunity to adapt play according to these limitations. We see kinesthetic literacy as having two major learning objectives: learning to move, and moving to learn [28]. Learning to move asks participants to focus on an understanding of the body in order to acquire the skills and techniques that are required to participate in physical activities. Doing so allows participants to take control of their body and to know its range and capacity for movement. Learning in this context often focuses on "fine-tuning" motor control [27, 29] and fundamental aspects of movement such as hand-eye coordination, coping with space, speed and distance. In moving to learn, the physical activity is the context for a means of learning. For example, in previous work [29], we explored how a tangible, exertion interface can be used to learn about basic science concepts such as the concept of acceleration. Doing so can reveal information about social skills, competition and cooperation, and knowing when and why different movement actions are appropriate and effective as well as contribute to an understanding how aspects such as "witting" transitions in performative behavior [26] can be applied in learning contexts.

\subsection{Performative interaction}

Designing for performative interaction should consider that performing in a clapping game focuses attention inward rather than outward. With our clapping game, transitions in performative interaction happen through the body - the performance frame is defined through points of impact. Transitions from observing to participating happen through memorizing songs and acquiring competency of clapping patterns or gestures. Transitions from participating to performing happen when participants deviate from or add to the known patterns and rhythms. Physical creativity happens when participants transition to performers - when the participants choose to deviate from the known patterns. Since this deviation happens through the physical exertion, we might consider this a form of showmanship. Showmanship is usually considered a dramatic 'mental game' that competitive people use in an exertion activity order to 'get into the head of their opponent' usually with the intention to win over an audience or crowd. However, playground clapping games are not designed for an audience - they are a form of "participatory performance" [30] rather than "presentation performance". The activity happens between two people, or multiple people facing inward, playing with each other rather than against each other. As such, there isn't any emphasis on mentally 'wearing down the opponent'. In fact, doing so would ruin the game as participants rely on each other to play the game. These kinds of bodily and social performances and actions also connect with forms of cultural capital [5] - the transmitted repertories of gesture, word and music that allow such activities to be invested with cultural meaning and the construction of identity.

\subsection{Believability}

During the iterative prototyping phases a number of technical design and usability issues arose which 
posed trade-offs in terms of development. For example, using the accelerometer-only solution to drive 3D graphics meant that we would need to "fake" the actual position of the user. This limitation means that the external representation, whether audio, visual or haptic, must be carefully designed in order to make the player perceive that their physical movements in the real world are being represented in the digital world. For example, most Wiimote games use this method of 'faking' physical gameplay. However, as players become more capable of more extreme physical activity, we will need to design systems that reflect performers increasing awareness of the technical or physical limitations within the range of known possibilities or probabilities.

\section{PROTOTYPE DESIGN}

The most significant technical challenge for Wii Clapping is in mapping various levels of granularity [27, 29]; how do different levels of Wii Clapping movement relate to the cultural reality of clapping movement? In our first experiments, we investigated how to understand and then program the basic units of each clapping movement. Each non-verbal dynamic (up/down; clap against/clap together, etc.) are basic units or clapping 'memes' and these clapping memes are programmable entities. What kinds of implications does this have for the level of specificity, or for the balance between real time recording of clapping and triggering simulated animations of clapping? Can the variables be made more salient?

\subsection{Software prototype}

The object of our iterative technology prototyping experiments was to examine this granularity. We began by assessing the orientation and positioning of the Wiimote in physical space and using this information to control visuals on a computer screen. In our initial design experiments, we connected two Wiimotes via Bluetooth to a laptop which was running an application written in Processing (processing. org) that used the Wiimote acceleration data to control a digital 3D object in any dimension or with varying magnitude (larger or smaller movements). The continuous (and very quick) variability and combination of magnitude, acceleration, orientation and position, made it difficult to perceive the objects' movement. We further experimented with changes in the objects' color, shape, dimension and adding visual markers. Eventually, we designed two 3D hands with palms facing downward.

Mapping acceleration data allowed us to correctly represent physical orientation in the digital world. However, this experiment highlighted the difficulties in using acceleration sensors when mapping the position of physical objects 3D digital space. Acceleration data cannot provide absolute position information (i.e. where an object is located in the real world). As a result, we used relative positioning (i.e. 'simulated' the position) of our digital objects - we fixed the 'start' position of our $3 \mathrm{D}$ objects to the middle of the screen so that the object 'bounced back' to the start position after each movement. Using relative positioning worked well for experimentation however, when applied to a twohanded representation, it presented many problems. For example, if we moved the Wiimote really quickly forward and backward, the digital object mirrored our movements however, if we move the Wiimote at a constant speed forward and backward, the digital object would not move at all on the screen. This is because an object moving at a constant speed has zero acceleration. This brings up an interesting technical consideration: if we 'fake' the start position of the digital hands, how is it possible to determine when a clap is going to take place? Will our solution need to anticipate clapping?

\subsection{Physical prototype}

The design of our prototype system has two important goals: to adapt existing playground games into digital format; and, to allow children to record and replay their own games. Our intention is to design an exertion interface that engages participants in intuitive, fluid, playful and 'natural' interaction taking into account both the verbal and non-verbal dynamics that result from interactions in and around the interface [26]. When developing our interface, we must consider that these 'natural' or 'intuitive' interactions might be rooted either in children's experience of traditional clapping and/or in their experience of mediated play with these kinds of interface/device. To design our interface, we used design guidelines from previous studies in designing performative tangible interaction [27], namely:

- Intuitive - there is a direct link between physical movement (clapping in the real world) and the audio/visual/haptic output of the system.

- Unobtrusive - the gloves are body-centric and move with the person interacting with them.

- Enticing - the interaction is visible to observers and they can easily enter into performative play simply by moving their hands. 
- Portable - our system requires a set of gloves with the electronics attached that can be carried in one hand, and one laptop.

- Robust - the gloves are shock-resistant, the software is designed to withstand crashes of subcomponents and does not rely on specialized drivers or hardware.

- Flexible - the system is designed to quickly adapt visual or audio output to suit the surrounding environment.
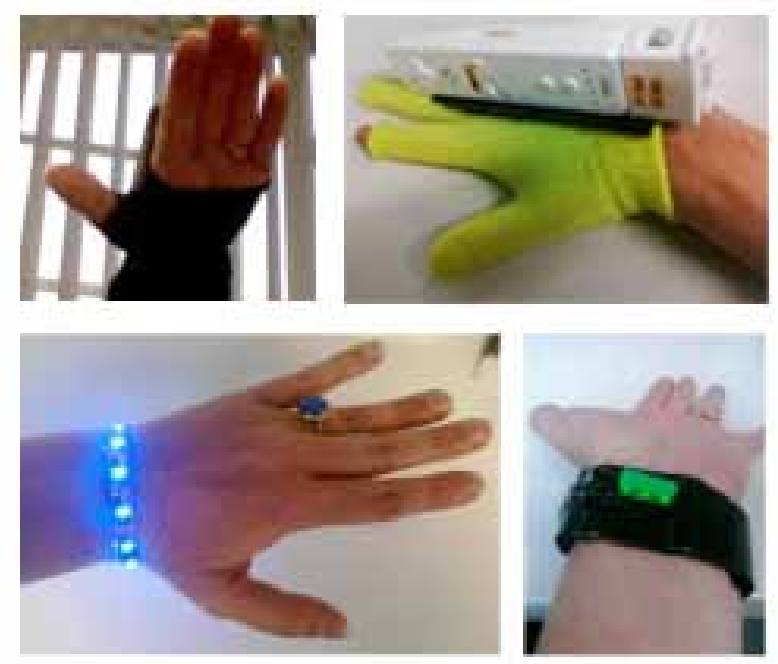

Figure 3. Prototypes for capturing motion.

Our initial prototyping involved designing a wearable (top, Figure 3) and wireless interface that explored the notion of 'natural' interaction. We experimented with attaching Wiimotes in various orientations and with/without infrared communication. In keeping inline with children's experience of videogames, we added a GUI (graphical user interface) as a navigation mechanism and mapped the physical Wiimote buttons to the digital GUI buttons. As mentioned above, an application was written in Processing to map movement in the physical world with movements in the digital world.

\subsection{Record and replay prototype}

Our current prototype system allows us capture, record and log movement data. We have designed our system so that a participant can replay this data (or any subset of the data) on the computer screen. In order to better understand the reams of collected data, we have written a prototype application for visualizing clapping data in $3 \mathrm{D}$. We have also experimented with recording and replaying audio files.

Audio of the clapping game I Went to a Chinese Restaurant was pre-recorded and triggered when a participant began the clapping game. The audio file was coupled with a text file which contained each word/line of the clapping game so that when the audio file plays, the words are synchronized on the screen. Important to note is that in our prototype application, the original timings are manually input into the text files. For many children, the words and tunes of the clapping games will be just as important as the actions. An important consideration must be how to cater to this need to ensure that children can input their own tunes/words and that movements are synchronized to the tunes/words. These design considerations are described below in the rulebound 'follow the leader' application written for our pilot study.

Additionally, we are experimenting with audio sounds, such as 'clapping' sounds which are triggered when a participant claps their hands together. An interesting point to consider is that 'clapping' has unique audio properties that are difficult to record/ reproduce - our initial recording of clapping did not sound like clapping at all! As such, we will need to carefully consider how children are going to record and replay clapping sounds.

\section{USER STUDY}

In this section of the paper, we focus on children's interaction with the Wiimotes and discuss the other activities more generally. The activities were designed for participatory design to explore: the links children made between their own movements and digital movements on the large-screen display; how the interface encouraged physical creativity; and, changes and improvements the children could imagine. At the beginning of the study, the children gathered together in one room and were given a brief explanation about the Wii Clapping prototype interface and about the prototype/ iterative development. They were then split into groups of three and taken to the three different stations. Flip and HD cameras were used to collect video data for later analysis.

\subsection{Participants}

Clapping on the playground is usually the preserve of girls $[4,16]$ and each girl has a different level of competency and knowledge about clapping games. Older girls often teach the younger girls how to play the games. We conducted our pilot study with both boys and girls ( 2 boys and 4 girls), aged 8-11, from a school in London. Two girls in our study had very high levels of knowledge about clapping games and knew different variations of the games. All of the girls had more knowledge/competency about clapping games and played clapping games more often than the boys. For our study, the participants worked in groups of two on three different activities with at least one investigator for approximately 45 minutes 
for each activity.

\subsection{Activities}

Each activity took place in a different room and each group spent approximately 15-20 minutes on one activity and then rotated to the next activity:

\subsubsection{Exploratory and mental mapping activity}

One child used two Wiimotes to play two different clapping activities (see Section 6.3). Children would switch between observing others playing with the interface and participating with the interface themselves. One child was asked to put on the Wii Clapping gloves and then asked to position their body in front of the large-screen display while the other child sat beside them (Figure 4).

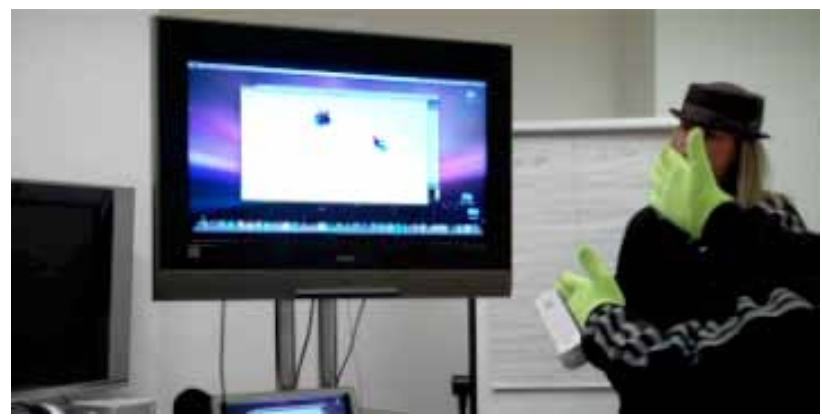

Figure 4. Children playing with the clapping interface.

The investigator opened up the first application on the screen and asked the child to move their hands around to try and get familiar with the interface. After a few minutes, the investigator asked the child to try and follow simple patterns of movement, for example, moving one hand up and the other down, moving them in the opposite directions, flipping their hands over, touching the ground, or moving fast and slow. The investigator asked what kind of games the children could imagine playing with the interface. After the first child had some time to play with the interface, the second child was given the opportunity to free play. After repeating the same experience, the children were then asked if they would like to play a clapping game. Both children were given an explanation of how the clapping game worked and one child was given the gloves. Children were told that the investigators were not keeping a "score", and that they would have an opportunity to play the game several times if they liked. Children were asked to comment on the game and asked what they would like to change.

\subsubsection{Visual reflection}

Children discussed various clapping games with two investigators and drew pictures (Figure 5). Children were asked about what clapping games they played on the playground and to think about what kind of games they could imagine playing with different kinds of technologies.
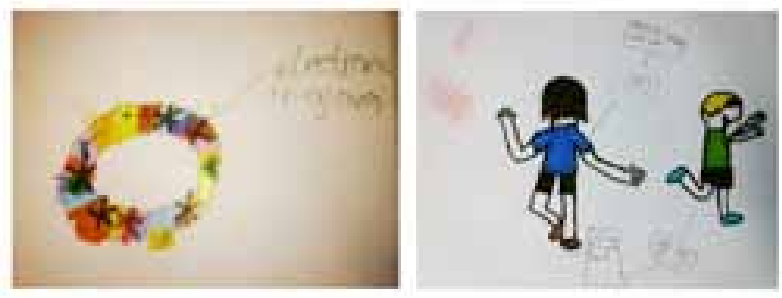

Figure 5. Children's drawings from the pilot study.

\subsubsection{Aural reflection}

An investigator interviewed children and recorded the interviews on video. During the interview, children were asked to reflect and comment on their experience using the interface (if they had done so), to imagine what kinds of activities they could do with the interface and to discuss and perform other clapping games with the investigators.

\subsection{Clapping applications}

Using the open source environment Processing, we developed two different clapping applications for the exploratory and mental mapping activity (Section 6.2.1):

\subsubsection{Emergent play}

In this exploratory interaction and mental mapping activity, children could move their own hands around in physical space to move the digital hands on the large-screen display to see the effects of their actions on the screen. In this activity we looked to promote free play to allow children to familiarize themselves with the interface.

\subsubsection{Rule-bound Play}

In this choreographed "follow the leader" activity, children were asked to try and follow the prerecorded computer-generated movements on the large-screen display.

An audio file played a pre-recorded version of the clapping game I Went to a Chinese Restaurant. Each line of the song appeared at the bottom of screen synchronized with the audio being played and a bouncing ball followed the words of the song. The prerecorded, computer-generated movements appeared as fully colored, mirrored hands on the large-screen display (identical to the free play activity). Children's hands appeared as 'ghost' grey hands, but rather than mirrored, they appeared in the same orientation and position as they would in the physical world (Figure 6). 


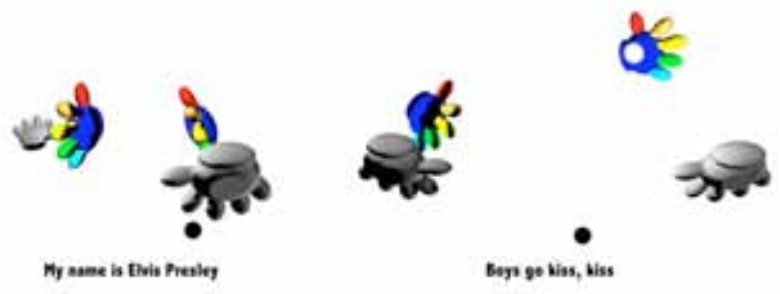

Figure 6. Play mode for I Went to a Chinese Restaurant.

\section{FINDINGS}

Activities were recorded on video and investigators wrote post study observations before reviewing and analyzing the video. Several interesting issues emerged from our study which point to the technical aspects that need addressing, as well as the key positive and negative aspects of the current design. We discuss these issues in the next sections.

\subsection{Rhythm, pace and punctuation}

In a clapping game, physical movement is intertwined with physical (and aural) rhythm [18]. Points of impact in a clapping game are the equivalent of a drumbeat or continuous pulse overlaid with pitch (the tune) and rhythm (associated with the words and their vocalization in the accompanying chant or song). However, the point of impact in our game is digital rather than physical - children punched at the air rather than hit another child's hands. This fact did not seem to affect the movement of children's clapping - children were still able to keep an even pace. However, since punctuation is the point of impact after a short, spontaneous burst of energy the current design was unable to detect and respond accordingly. Our system could detect and respond to changes in speed but not the point of impact. With our current design we were unable to tell if the changes in speed were due to a change in direction, or hitting something. If we consider that all clapping games rely on understanding the point of impact and very quick changes in direction then we need to consider how to design our interface to take in to account the virtual point of impact and speed, directionality and magnitude of movement.

\subsection{Familiarity and physical affordance}

Unlike a previous Wiimote study [29], children's familiarity with Nintendo Wiiremote games did not seem to hinder or restrict interaction. Children were inventive with their movements regardless of seeing the Wiimote fully exposed on top of the glove or being told that they needed to face the screen to 'see' their movements to map movements to the digital hands. Children would often point their fists forward saying "I feel like a superhero", or act like a robot or perform karate moves on another person. Despite sometimes being 'outside' of the 'zone of interaction' they did not seem to care - they were more interested in telling the investigators what they would like it to do, rather than what it was showing on the screen.

Another aspect to consider is the familiarity of traditional clapping games. In the rule-bound play activity, we had to tell the children that the start position of the digital hands was lying flat with palms facing down. This position is not the same start position of most traditional clapping games nor is it the same start position of any Wiimote game. Children found it difficult to play the game without any orientation and positioning markers or any indication of whether they were in the 'correct' position while playing the game. This point was closely related to the loci of attention (discussed in Section 7.3).

The range of children's hand size is quite significant. Some children had to hold their hands differently because the weight and size of the physical device was just too large for their hands. This of course affected the digital representation - the one to one mapping of the $X Y Z$ axis movement and digital representation was then inaccurate. Designing a glove that is suitable for a large range of children may not take advantage of the simplicity and affordance [14] of the original Wiimote design. As such, we will consider if our design is unnecessarily complex and if other input methods might be more suitable for our purposes.

\subsection{Loci of attention}

In a traditional clapping game, children face each other and look at each other's eyes, not always at each other's hands, particularly when they become 'experts'. The current prototype forces children to look at the digital hands on the screen to make the link between their own movements and movements on the screen. Children suggested that 'digital guides' or markers might be useful for visual, audio or haptic feedback and related this to the arrows and digital markers in games like in Konami Dance Dance Revolution and Guitar Hero. Some children were able to produce the clapping sound very quickly and then they repeated the clapping action that they needed to do to produce the sound continuously but without looking at the screen. Appropriate audio or haptic feedback (see 27]) could provide an alternative feedback modality so that children would not need to face the screen to interact with other players.

\subsection{Fluid frame of reference}

Interaction with the Wiimote in our study required action in 3D space and as such orientation and positioning in real space must be a consideration as well as orientation in the digital space. However, 
unlike traditional Wiimote games which combine grip and grasp with pressing buttons to get the desired digital effect, in our game the controller moves with and around the body [e.g. [27]] and gestures are fluid rather than pre-defined. Like the continuous nature of the data flow, participants continuously moved their bodies and the Wiimote around the space and in many cases became increasingly physical as they became more familiar with the interface (e.g. jumping up and down). However, because participants were able to move the controller in 3D space without any physical boundaries, the screen was the only point of reference from which they could orient and position themselves or the controller.

\section{FUTURE CONSIDERATIONS}

Physical creativity presents a new form/class of interaction that we have successfully demonstrated using a novel exertion interface for allowing children to record and replay clapping games. However, the system requires extensive further development and testing for it to be fully functional and robust.

In terms of technical aspects, the most problematic issue with using Wiimotes is in capturing $3 \mathrm{D}$ and multiple degrees of movement at very high speeds, and in particular, on the $Z$ axis (moving hands forward and backward). Our initial experiments highlight that Wiimotes cannot be used to identify absolute hand position in 3D. Currently, we are developing a solution that is low-fi and low-cost using Wiimotes and a vision-tracking application written in Processing (bottom, Figure 4). Preliminary tests show that despite the known constraints such as environmental lighting, our initial prototype is sufficiently robust for capturing and analyzing movement data. We will present our findings of our current development and user testing in future publications.

In our next design phase, we will need to consider: synchronicity: How to sync text, sounds, images and movement data; physical device: most comfortable/ natural solution for orientation/position; digital representation: refining color, shape, dimensionality of digital representations; granularity: mirroring (simulated/real) movement data so that it allows for 'natural' interaction; interpretation: one to many interpretations of the same/different data; scalability: from one to many participants, at different times/ locations. As each of the above issues require detailed analysis and development time, we will need to strike a balance between what is feasible for prototype development, and what will be considered in future developments.

Some questions emerging from our initial experiments are: how will children reflect or respond to seeing their own or others' contributions? How will this affect the kinds of games or skills that they develop over time? How will record and replay affect physical creativity and performative interaction? How does this kind of mediated performance relate to children's experience of both traditional games and computer games? We will explore these and other issues in future publications using various objecttracking and positioning techniques. In addition, we will be further investigating gender and gaming [11] as well as the concept of clapping 'memes' - such as, are these units the process that transmission teaches, or that the creative process recombines, or which the Wii makes available? How do these memes relate to Burn's discussion [12] of the units of oral transmission conceived in 'oral-formulaic' composition? We will present our findings in future publications.

\section{ACKNOWLEDGEMENTS}

Funded by the AHRC Beyond Text program "Playground Games and Songs in the New Media Age" project. Thank you to: Andrew Burn, Julia C. Bishop and Chris Richards for creative input and editing; Christopher Hatton Primary School; and, to BigDog Interactive for use of prototyping equipment.

\section{REFERENCES}

[1] Activition Guitar Hero. http://www.guitarhero.com [Last checked: March 25, 2010].

[2] Benford, S., Crabtree, A., Reeves, S., Flintham, M., Drozd, A., Sheridan, J.G. and Dix, A. 2006. The frame of the game: Blurring the boundary between fiction and reality in mobile experiences. In Proc. of CHI'06 (Montreal, Canada, April 22-27, 2006). ACM, New York, NY, 427-436.

[3] Behrenshausen, B.G. 2007. Toward a (Kin) Aesthetic of Video Gaming: The Case of Dance Dance Revolution. Games and Culture, 2 (4), 335354.

[4] Bishop, J. and Curtis, M. (eds). 2001. Play Today in the Primary School Playground: Life, Learning and Creativity. Open University Press, Buckingham.

[5] Bourdieu, P. 1984. Distinction: a Social Critique of the Judgment of Taste (R. Nice, Trans.). Harvard University Press, Cambridge, MA.

[6] British Library Sound Archive Catalogue. (Opie Collection C898) http://cadensa.bl.uk/cgi-bin/webcat [Last checked: June 10, 2010].

[7] Burn, A. and Durran, J. 2007. Media Literacy in Schools. Paul Chapman, London, UK.

[8] Caillois, R. 2001. Man, play and games (Les jeux et les homes) (M. Barash, Trans.). University of Illinois Press, Chicago, IL. (Original work published 1958). [9] Candy, L. and Hori, K. 2003. The digital muse: $\mathrm{HCl}$ in support of creativity: creativity and 
cognition comes of age: towards a new discipline, Interactions, 10 (4), 44-54.

[10] Candy, L. and Edmonds, E. 2002. Explorations in Art and Technology, Springer-Verlag, London, UK.

[11] Carr, D., Buckingham, D., Burn, A. and Schott G. 2006. Games and Gender. In Computer Games: Text, Narrative and Play. Polity Press, Cambridge, UK.

[12] Children's Playground Games and Songs in the New Media Age. Interim Conference (London, February 25, 2010). http://projects.beyondtext. ac.uk/playgroundgames/ [Last checked: June 10, 2010].

[13] Dix, A., Sheridan, J.G., Reeves, S., Benford, S. and O'Malley, C. 2006. Formalising Performative Interaction. Lecture Notes in Computer Science, 1525. Springer Verlag, Germany.

[14] Gibson, J. J. 1977. The Theory of Affordances. In Perceiving, Acting, and Knowing: Toward an Ecological Psychology. (R. Shaw and J. Bransford Eds.). Lawrence Erlbaum Associates, Hillsdale, NJ.! [15] Giddings, S. Circuits: a video essay. Level Up Conference (University of Utrecht, The Netherlands, November 4-7, 2003).

[16] Grugeon, E. 2001. 'Girls' traditional games on two playgrounds', Play Today in the Primary School Playground: Life, Learning and Creativity. (J.C. Bishop and M.Curtis Eds.). Open University Press, Buckingham.

[17] Konami Dance Dance Revolution. http://www. konami.com [Last checked: March 25, 2010].

[18] Marsh, K. 2008. The Musical Playground. Global Tradition and Change in Children's Songs and Games. Oxford University Press, London, UK.

[19] Mueller, F., Agamanolis, S. and Picard, R. 2002. Exertion interfaces for sports over a distance. In Proc. of UIST'02 (Paris, France, October 27-30, 2002). ACM, New York, NY.

[20] Mueller, F., Gibbs, M. R. and Vetere, F. Taxonomy of Exertion Games. In Proc. of OZCHI'08 (Queensland, Australia 2008), 263-266.

[21] Ninetendo Wii Remote. http://www.nintendo. com/wii [Last checked: March 25, 2010].

[22] Opie, I. and Opie, P. 1951. The Oxford Dictionary of Nursery Rhymes. Oxford University Press, Oxford, UK.

[23] Opie, I. and Opie, P. 1959. The Lore and Language of School-children. Clarendon Press, Oxford, UK.

[24] Opie, I. and Opie, P. 1985. The Singing Game. Oxford University Press, Oxford, UK.

[25] Salen, K. and Zimmerman, E. 2004. Rules of Play: Game Design Fundamentals. MIT Press, Cambridge, MA.

[26] Sheridan, J.G. 2006. Digital Live Art: Mediating Wittingness in Playful Arenas. Doctoral Thesis. Lancaster University, Lancaster, UK.

[27] Sheridan, J.G. and Bryan-Kinns, N. 2008. Designing for Performative Tangible Interaction. Int.
Jour. of Arts and Technology. 1(3/4), 288-308.

[28] Sheridan, J.G. and Mueller, F. 2010. Fostering Kinesthetic Literacy through Exertion in Whole Body Interaction. In Proc. of the Workshop on Whole Body Interaction, CHI'10, (Atlanta, USA, April 10-11, 2010). [29] Sheridan, J.G., Price, S. and Pontual-Falcão, T. Using Wii Remotes as Tangible Exertion Interfaces for Exploring Action-Representation Relationships. In Proc. of the Workshop on Whole Body Interaction, CHI'09 (Boston, USA, April 4, 2009).

[30] Turino, T. 2008. Music as Social Life: The Politics of Participation. University of Chicago Press, Chicago, IL.

[31] Vygotsky, L. 1978. Mind in society: The development of psychological processes. Harvard University Press, Cambridge, MA.

[32] Wessel, D. and Wright, M. 2002. Problems and Prospects for Intimate Musical Control of Computers. Computer Music Journal, 26 (3), 11-22.

[33] Willett, R., Robinson, M. and Marsh, J. (eds). 2008. Play, Creativity and Digital Cultures. Routledge, London, UK. 